THE DISCUSSION AT THE MEDICAL SOCIETY ON THE OPERATIVE TREATMENT OF
CHRONIC DISEASE OF THE UTERINE
APPENDAGES. To the Editors of THE LANCET.

SIRs,-Having unavoidably been prevented from attending the above adjourned discussion on Monday evening last, I would like, with your permission, to briefly remark on one or two points in connexion with Dr. W. Duncan's paper on the subject in question.

In the first place, with regard to Dr. Duncan's tabulated series of cases, I think it a matter for regret that no indication whatever was therein afforded as to the dates on which the operations thus recorded were performed. Dr. Duncan, in reply to an inquiry by the President as to whether the cases-numbered consecutively from one to thirty-comprised all those of the kind which had been thus treated by him, stated at the meeting on Jan. 12th" that " his earlier results in all cases of abdominal section had been so awful that he would not like to publish them." In other respects the cases were said to be consecutive up to the date of writing his paper. While giving Dr. Duncan full crediv for the frankness of his avowal on this point, I venture to think that his omission was an unfortunate one, since statistics thus compiled cannot be of much scientific value as to the comparative risks and advantages of the operation to which they refer. If we turn back to the history of ovariotomy in this country thirty years ago we learn that what chiefly tended to establish the operation upon a firm basis as a wellrecognised surgical procedure in the eyes of the profession at large was the fact that each case in the practice of $\mathrm{Mr}$. Spencer Wells, whether successful or unsuccessful, was duly and faithfully recorded by him from the commencement of his work in this field; and, so far as I know, the good rule then initiated has up till now been followed by his successors when bringing forward statistical results of their work in any special branch of abdominal surgery. It seems to me that any departure from such a rule must inevitably destroy the value of statistics in any given instance, and it is therefore to be hoped that the plan here adopted by Dr. Duncan may not be followed by other operators. The remaining subject to which I would allude in connexion with this paper is the comparatively large number of operations which appear to have been found necessary in Dr. Duncan's practice for the relief of suffering presumably connecced with the state of the uterine appendages The absence already noted of any indication as to the period covered by the work recorded makes it impossible to judge as to the relative proportion which these operations might bear to the total number of Dr. Duncan's abdominal sections during the same period, or from the date when he first began to operate. On neither of these latter points, however, does his paper afford us any information.

In order to estimate the comparative frequency of these operations in other hands than those of the author of this paper I have examined the register of the Samaritan Free Hospital, with a view to ascertaining some definite information on this subject. I find that in 1890, out of a total of 141 abdominal sections, the number of operations for removal of diseased uterine appendages (one or both) was exactly fourteen-a proportionate rate of as nearly as possible 10 per cent. on the total. These figures, considered in relation to the twenty-three hospital operations recorded by Dr. Duncan-which comprise seventeen cases of complete and three of incomplete removal of the uterine appendages, to the exclusion of two cases of ovarian cyst (Nos. 5 and 17) and one exploratory operation (No. 21)-would apparently indicate one or other of two things: either that the surgical staff of the Samaritan Hospital do not frequently enough resort to operative treatment for the cure of the diseases in question, or else that the number of urgent cases of such nature, unrelievable by rest and medical treatment, who apply at the Middlesex and Waterloo-road Hospitals, is greatly in excess of those to be met with at the Samaritan Free Hospital. In my own belief neither of these interpretations can be considered correct. The true explanation lies in the spirit of restless surgery now so prevalent that, unless restrained, it will, I fear, bring into disrepute an operation which, when judiciously undertaken in properly selected instances, nay prove a most valuable means of restoration to health.

I am, Sirs, yours faithfully,

Queen Anne-street, W., Jan. 28th, $1891 . \quad$ W. A. MEREdith.

\section{ILEOSTOMY AND INTUSSUSCEPTION.}

\section{To the Editors of THE LANCET.}

SrRs,-In your issue of last week, page 221, my friend Mr. Reeves gives a short description of a case in which he had performed ileostomy in a man suffering from cancer of the cæecum, on similar lines to those described by Mr. Bryant in a former number of THE LANCET. By adopting this method of treatment a fæecal fistula is formed, which is most distressing to the patient, and, being situated in the small intestine, somewhat difficult to manage. To obviate this I would strongly advocate the operation of ileocolostomy, either by approximation of the ileum to some portion of the colon below the disease by means of decalcified bone plates as suggested and practised by Dr. Senn, or by dividing the ileum some three inches above the ileo-creal valve, closing the distal end and implanting the proximal end into the colon below the disease. This latter operation I performed upon a patient some eighteen months ago, details of which will shortly be reported in your columns. By adopting this operation a fæcal fistula is avoided and the patient placed in as comfortable a position as possible for the remainder of his life. In the discussion at the Clinical Society on Jan. 9th, which followed Mr. Lockwood's paper on a case of Acute Intussusception, I was pleased to see Mr. Barker alluded to a method of treating those cases, when the intussusception could not be reduced, by making a longitudinal incision through the intussuscepiens and then cutting away the inner intussuscepted part, the original incision being closed by sutures. This is a plan of treatment which I have advocated for some time, but, like Mr. Barker, have not had an opportunity of putting it into practice. In carrying out the operation, however, I would suggest that a few Lembert sutures should be inserted, to unite the intestine at its junction with the intussuscepiens, for fear of the accident of its slipping after the removal of the intussuscepted part; this part, if small, might be withdrawn through the incision made in the intussuscepiens, or, if extensive and extendiug low down in the colon, might by manipulation be passed downwards and withdrawn through the rectum.-I am, Sirs, yours faithfully,

Upper Wimpole-street, $\mathrm{W}$. FRED. BOWREMAN J'ESSETT, F.R.C.S.

\section{"THE THROAT AND NOSE AND THEIR DISEASES." \\ To the Editors of THE LANCET.}

SIRs,-In thanking you for the lengthened and, on the whole, very favourable notice of iny work, I am sorry to be obliged to point out that there are certain numerous instances of misrepresentation of matters of fact. These are due probably to the circumstance that your reviewer has imperfectly read the book, since an entirely different con. struction would have been placed on some of my quoted remarks had he even read the word before or the line following some of those that are criticised. To cite only two instances of a minor character-when he asks why I do not treat tuberculosis of the nose at length, he does not recognise that I immediately proceed to say that "it is but rarely if ever primary" (p. 580), and he also ignores the circumstance that I have exhaustively treated the subject of tubercle as affecting the throat, independently of the considerable attention given to lupus both in the throat and nose. Again, in speaking of my modified views with regard to the etiology of diphtheria, he quotes the word "probable" with a parenthetic " sic," whereas the words I use are "more probable" (p. 335).

To come, however, to something more serions. Your reviewer says, "The only instruments for treating bony or cartilaginous septal excrescences advocated are Curtis's nasal trephines ...... while no mention is made of the motive power ;" and that "Bosworth's saws are not men. tioned." As a matter of fact, after referring to Adams's operation of refracturing the septum, I commence my remarks on treatment by recommending "removal of the 